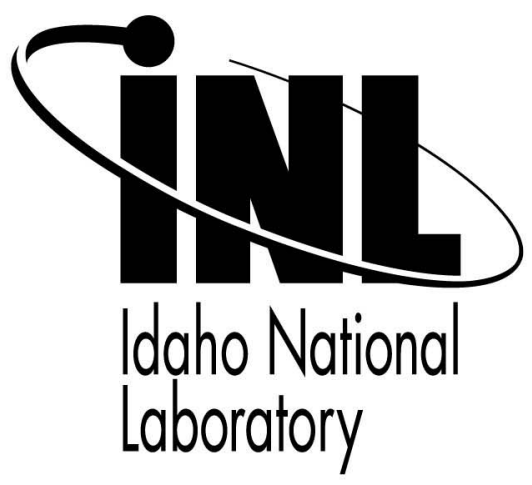

\title{
Engineering High-Fidelity Residue Separations for Selective Harvest
}

\section{ASABE Annual International Meeting}

Kevin L. Kenney

Christopher T. Wright

Reed L. Hoskinson

J. Richard Hess

David J. Muth, Jr.

July 2006

This is a preprint of a paper intended for publication in a journal or proceedings. Since changes may be made before publication, this preprint should not be cited or reproduced without permission of the author. This document was prepared as an account of work sponsored by an agency of the United States Government. Neither the United States Government nor any agency thereof, or any of their employees, makes any warranty, expressed or implied, or assumes any legal liability or responsibility for any third party's use, or the results of such use, of any information, apparatus, product or process disclosed in this report, or represents that its use by such third party would not infringe privately owned rights. The views expressed in this paper are not necessarily those of the United States Government or the sponsoring agency. 
Author(s)

\begin{tabular}{|l|l|l|l|l|}
\hline First Name & Middle Name & Surname & Role & Email \\
\hline Kevin & L. & Kenney & $\begin{array}{l}\text { Non-ASABE } \\
\text { Member }\end{array}$ & $\begin{array}{l}\text { kevin.kenney } \\
\text { @inl.gov }\end{array}$ \\
\hline
\end{tabular}

Affiliation

\begin{tabular}{|l|l|l|}
\hline Organization & Address & Country \\
\hline Idaho National Laboratory & $\begin{array}{l}\text { P.O. Box 1625, MS 2210 Idaho } \\
\text { Falls, ID 83415-2210 }\end{array}$ & U.S.A \\
\hline
\end{tabular}

Author(s)

\begin{tabular}{|l|l|l|l|l|}
\hline First Name & Middle Name & Surname & Role & Email \\
\hline Christopher & T. & Wright & $\begin{array}{l}\text { Non-ASAE } \\
\text { Member }\end{array}$ & $\begin{array}{l}\text { christopher.w } \\
\text { right@inl.gov }\end{array}$ \\
\hline
\end{tabular}

Affiliation

\begin{tabular}{|l|l|l|}
\hline Organization & Address & Country \\
\hline Idaho National Laboratory & $\begin{array}{l}\text { P.O. Box 1625, MS 2210 Idaho } \\
\text { Falls, ID 83415-2210 }\end{array}$ & U.S.A \\
\hline
\end{tabular}

Author(s)

\begin{tabular}{|l|l|l|l|l|}
\hline First Name & Middle Name & Surname & Role & Email \\
\hline Reed & L. & Hoskinson & $\begin{array}{l}\text { ASAE } \\
\text { Member }\end{array}$ & $\begin{array}{l}\text { reed.hoskins } \\
\text { on@inl.gov }\end{array}$ \\
\hline
\end{tabular}

\section{Affiliation}

\begin{tabular}{|l|l|l|}
\hline Organization & Address & Country \\
\hline Idaho National Laboratory & $\begin{array}{l}\text { P.O. Box 1625, MS 2210 Idaho } \\
\text { Falls, ID 83415-2210 }\end{array}$ & U.S.A \\
\hline
\end{tabular}

The authors are solely responsible for the content of this technical presentation. The technical presentation does not necessarily reflect the official position of the American Society of Agricultural and Biological Engineers (ASABE), and its printing and distribution does not constitute an endorsement of views which may be expressed. Technical presentations are not subject to the formal peer review process by ASABE editorial committees; therefore, they are not to be presented as refereed publications. Citation of this work should state that it is from an ASABE meeting paper. EXAMPLE: Author's Last Name, Initials. 2006. Title of Presentation. ASABE Paper No. 06xxxx. St. Joseph, Mich.: ASABE. For information about securing permission to reprint or reproduce a technical presentation, please contact ASABE at rutter@asabe.org or 269-429-0300 (2950 Niles Road, St. Joseph, MI 49085-9659 USA). 
Author(s)

\begin{tabular}{|l|l|l|l|l|}
\hline First Name & Middle Name & Surname & Role & Email \\
\hline J. & Richard & Hess & $\begin{array}{l}\text { Non-ASAE } \\
\text { Member }\end{array}$ & $\begin{array}{l}\text { jrichard.hess } \\
\text { @inl.gov }\end{array}$ \\
\hline
\end{tabular}

\section{Affiliation}

\begin{tabular}{|l|l|l|}
\hline Organization & Address & Country \\
\hline Idaho National Laboratory & $\begin{array}{l}\text { P.O. Box 1625, MS 2210 Idaho } \\
\text { Falls, ID 83415-2210 }\end{array}$ & U.S.A \\
\hline
\end{tabular}

Author(s)

\begin{tabular}{|l|l|l|l|l|}
\hline First Name & Middle Name & Surname & Role & Email \\
\hline David & J. & Muth & Non-ASAE Member & dmuthjr@iastate.edu \\
\hline
\end{tabular}

\section{Affiliation}

\begin{tabular}{|l|l|l|}
\hline Organization & Address & Country \\
\hline lowa State University & $\begin{array}{l}3030 \mathrm{H} . \text { M. Black Engineering } \\
\text { Bldg. Ames, IA 50011-2160 }\end{array}$ & U.S.A \\
\hline
\end{tabular}

\section{Publication Information}

\begin{tabular}{|l|l|}
\hline Pub ID & Pub Date \\
\hline 066171 & 2006 ASABE Annual Meeting Paper \\
\hline
\end{tabular}

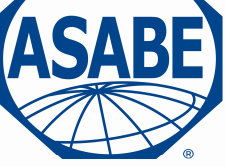

American Society of

Agricultural and Biological Engineers

\section{An ASABE Meeting Presentation}

Paper Number: 066171

The authors are solely responsible for the content of this technical presentation. The technical presentation does not necessarily reflect the official position of the American Society of Agricultural and Biological Engineers (ASABE), and its printing and distribution does not constitute an endorsement of views which may be expressed. Technical presentations are not subject to the formal peer review process by ASABE editorial committees; therefore, they are not to be presented as refereed publications. Citation of this work should state that it is from an ASABE meeting paper. EXAMPLE: Author's Last Name, Initials. 2006. Title of Presentation. ASABE Paper No. 06xxxx. St. Joseph, Mich.: ASABE. For information about securing permission to reprint or reproduce a technical presentation, please contact ASABE at rutter@asabe.org or 269-429-0300 (2950 Niles Road, St. Joseph, MI 49085-9659 USA). 


\title{
Engineering High-Fidelity Residue Separations for Selective Harvest
}

\section{Kevin L. Kenney}

Idaho National Laboratory, P.O. Box 1625, Idaho Falls, ID 83415-2210, kevin.kenney@inl.gov

\section{Christopher T. Wright, Ph.D.}

Idaho National Laboratory, P.O. Box 1625, Idaho Falls, ID 83415-2210, christopher.wright@inl.gov

\section{Reed L. Hoskinson, Ph.D.}

Idaho National Laboratory, P.O. Box 1625, Idaho Falls, ID 83415-2210, reed.hoskinson@inl.gov

\section{J. Richard Hess, Ph.D.}

Idaho National Laboratory, P.O. Box 1625, Idaho Falls, ID 83415-2210, christopher.wright@inl.gov

\section{David J. Muth, Jr.}

Iowa State University, 3030 H. M. Black Engineering Bldg. Ames, IA 50011-2160, dmuthjr@iastate.edu

\author{
Written for presentation at the \\ 2006 ASABE Annual International Meeting \\ Sponsored by ASABE \\ Oregon Convention Center \\ Portland, Oregon \\ 9 - 12 July 2006
}

Poster presented at $28^{\text {th }}$ Symposium on Biotechnology for Fuels and Chemicals, Nashville, TN, April 30 - May 3, 2006.

\begin{abstract}
Composition and pretreatment studies of corn stover and wheat stover anatomical fractions clearly show that some corn and wheat stover anatomical fractions are of higher value than others as a biofeedstock. This premise, along with soil sustainability and erosion control concerns, provides the motivation for the selective harvest concept for separating and collecting the higher value residue fractions in a combine during grain harvest. This study recognizes the analysis of anatomical fractions as theoretical feedstock quality targets, but not as practical targets for developing selective harvest technologies. Rather, practical quality targets were established that identified the residue separation requirements of a selective harvest combine. Data are presented that shows that a current grain combine is not capable of achieving the fidelity of residue fractionation established by the performance targets. However, using a virtual engineering


approach, based on an understanding of the fluid dynamics of the air stream separation, the separation fidelity can be significantly improved without significant changes to the harvester design. A virtual engineering model of a grain combine was developed and used to perform simulations of the residue separator performance. The engineered residue separator was then built into a selective harvest test combine, and tests performed to evaluate the separation fidelity. Field tests were run both with and without the residue separator installed in the test combine, and the chaff and straw residue streams were collected during harvest of Challis soft white spring wheat. The separation fidelity accomplished both with and without the residue separator was quantified by laboratory screening analysis. The screening results showed that the engineered baffle separator did a remarkable job of effecting high-fidelity separation of the straw and chaff residue streams, improving the chaff stream purity and increasing the straw stream yield.

Keywords. selective harvest, single-pass harvest, feedstock engineering, biofeedstock, virtual engineering, computational engineering, virtual reality 


\section{Introduction}

Studies conducted at NREL (corn stover studies), INL (wheat stover studies) and University of Kentucky (corn stover and wheat stover studies) all demonstrate that glucan and xylan sugar content vary among the biomass anatomical fractions. The University of Kentucky data is shown in Figure 1, and is of interest because the corn and wheat stover compositional analysis was conducted using an identical analytical procedure.

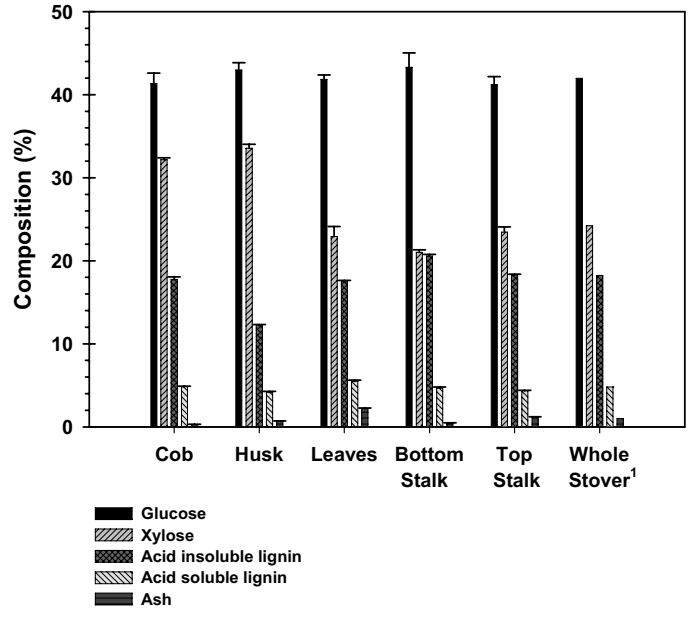

(a)

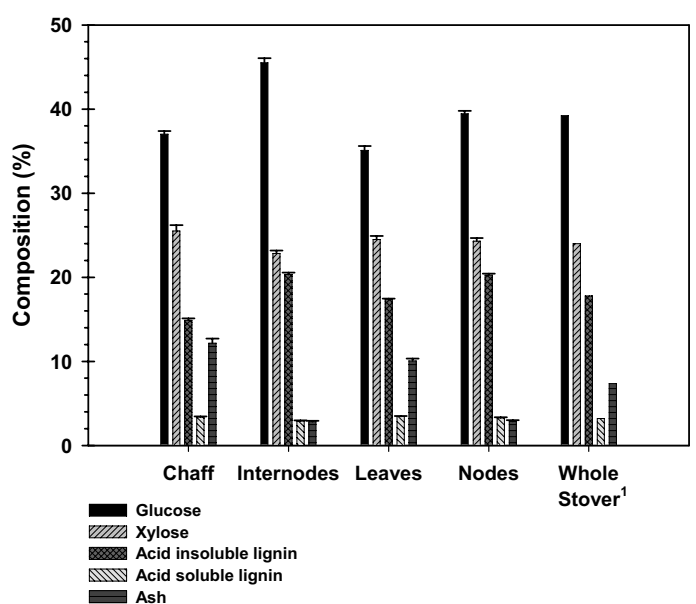

(b)

Figure 1. Glucose, xylose, acid insoluble lignin, acid soluble lignin, and ash content of corn stover (a) and wheat stover (b) anatomical fractions. ('Whole stover is calculated using component distribution.) With permission, Mike Montross, University of Kentucky.

These studies show that glucan and xylan sugar content variability can be greater than $10 \%$ for stover and cereal straw anatomical fractions. Lignin content variability between anatomical fractions can approach $6 \%$. The compositional variability of these constituents between anatomical fractions appears to be significant and have some degree of stable predictability that could be exploited to improve feedstock structural carbohydrate content. Since ethanol yield is a function of feedstock structural carbohydrate content, biomass anatomical fractions of higher product yield can have a significant beneficial impact on minimum ethanol selling price.

The composition studies of anatomical fractions clearly show that some corn and wheat stover anatomical fractions are of higher value than others. This premise, along with soil sustainability and erosion control concerns, provides the basis of the selective harvest concept for separating and collecting the higher value residue fractions in a combine during grain harvest. However, anatomical fractions are obtained by hand separation of the stover in a laboratory, but this level of fractionation cannot be achieved with current combine harvesters or any other preprocessing equipment. Developing selective harvest technologies could take on the task of developing high-fidelity anatomical fractionation technologies for combine harvesters, but this is a significant engineering challenge, not to mention the corresponding technological concerns involving collection, handling and transportation issues. Rather, the more appropriate, logical, and necessary task for developing the selective harvest technologies is to first evaluate and optimize the residue fractionation that currently takes place in a grain combine. 
Although a grain combine is not capable of the high-fidelity anatomical fractionation, a degree of anatomical fractionation does occur. Consider the residue fractionation of wheat stover for example. The four anatomical fractions of wheat stover from Figure 1(b) consist of chaff (hulls, awns), leaves, internodal stem and nodes. As the wheat stover passes through the combine and the grain is harvested, the anatomical fractions are roughly separated into two residue fractions - chaff and straw. The chaff fraction is generally comprised of the non-stem tissues (leaves, sheaths, hulls and awns), and the straw fraction is generally comprised of the stem tissues (internodal stem and nodes). Using the compositions of the anatomical fractions in Figure 1(b) and the anatomical distribution shown in Figure 2(b), we can estimate the composition of the two residue streams. This is shown in Figure 3(a).

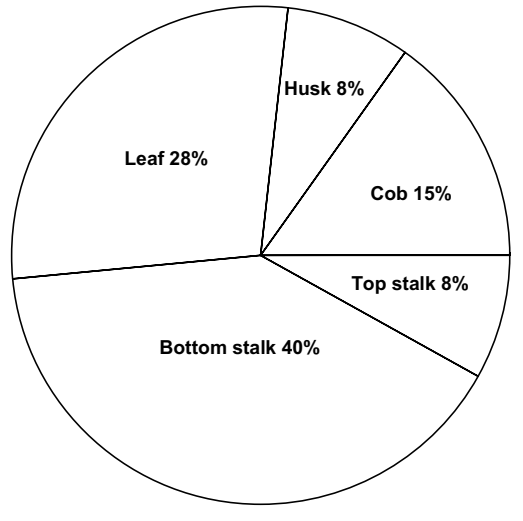

(a)

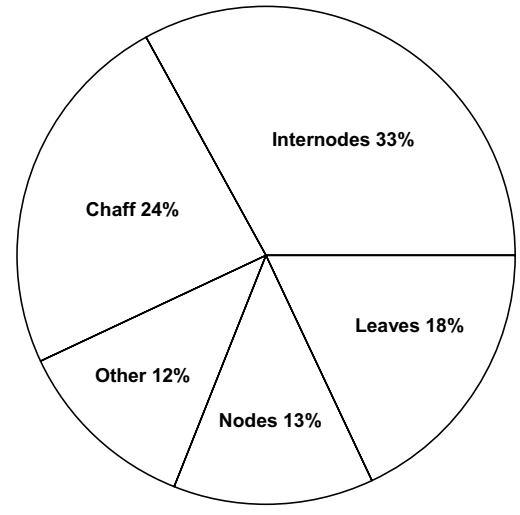

(b)

Figure 2. Distribution of corn stover (a) and wheat stover (b) fractions determined by hand separation. With permission, Mike Montross, University of Kentucky.

A similar analysis of corn stover fractionation is more complicated since the entire plant does not pass through the combine as occurs with cereal crops. Rather, the corn head on a combine separates the ear from the rest of the plant, so only the ear (cob, grain and husk) and some of the leaves and upper stalk pass through the combine. Therefore, defining the composition of the residue streams is difficult since the amount of biomass passing through the combine is variable. However, numerous researchers (Quick, 2002; Shinners, 2005) have investigated single-pass corn harvest where the entire plant was passed through the combine and the corn separated from the stover. It does not make sense to consider selective harvest without selecting stover fractions from the entire plant; therefore this analysis is based on the singlepass concept where, like wheat stover, the entire plant passes through the machine. In this scenario the five anatomical fraction of corn stover (cob, husk, leaves, bottom stalk and top stalk) are separated into two residue fractions - chaff and cob/stalk. The chaff fraction is generally comprised of husks and leaves, and the cob/stalk fraction is generally comprised of the cobs and stalks. Using the compositions of the anatomical fraction in Figure 1(a) and the anatomical distribution shown in Figure 2(a), we can estimate the composition of the two residue streams. This is shown in Figure 3(b).

The preceding discussion describes the highest fidelity corn and wheat stover residue fractionation we can expect from current combine harvesters. Data will be presented though that shows that a current grain combine is not capable of achieving this fidelity of residue fractionation. However, the objective of this task is to show that through a computational engineering approach, based on an understanding of the fluid dynamics of the air stream 


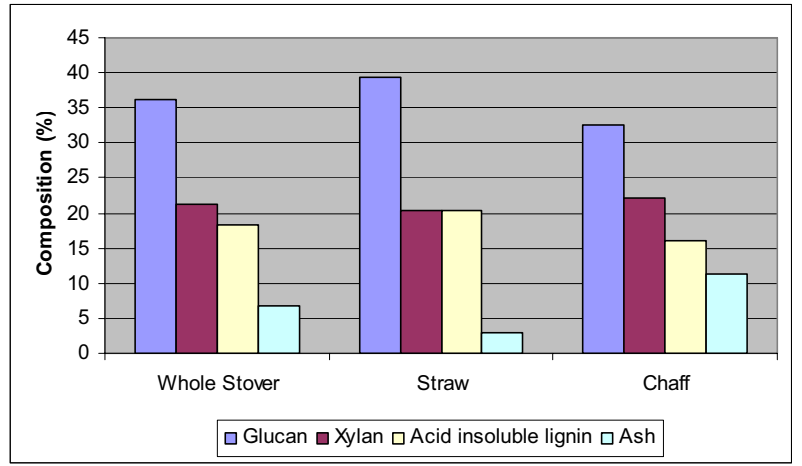

(a)

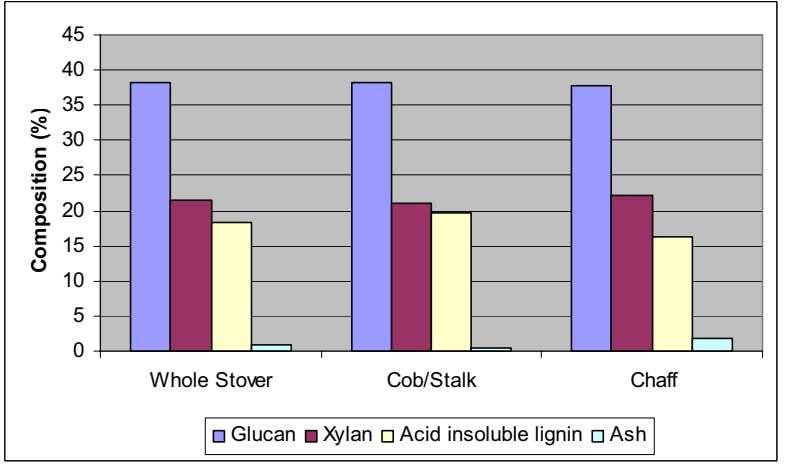

(b)

Figure 3. Theoretical compositions of combine residue streams assuming perfect separation of the anatomical fractions of wheat stover (a) and corn stover (b).

separation, the separation fidelity can be significantly improved without significant changes to the harvester design. However, the relevance of this work is not in the development of the computational tool or even the approach. Rather, the relevance is in demonstrating the value of selective harvest, not according to performance targets established by the analysis of anatomical fractions, but according to performance targets established on potential harvester fractionation. However, as will be shown in the following sections, the computational approach was necessary for accomplishing high-fidelity residue separation and demonstrating the true potential of selective harvest with current harvester technology.

\section{Background and Objectives}

A prior INL project funded by the Idaho Department of Water Resources (IDWR), evaluated, and attempted to optimize, the residue fractionation of combine harvesters to improve feedstock quality for the thermo-chemical platform (Hoskinson, 2005; Hess, 2004). Tests were performed by feeding bales of wheat straw (Westbred 936) into a stationary combine, and collecting the discharged chaff and straw streams via conveyers, tarps, etc. Using baffles and other machine adjustment measures, the best achievable anatomical fractionation of wheat straw stems was between $70-80 \%$ straw stem purity (i.e., $20-30 \%$ of the straw stream consisted of chaff material). These separation processes also resulted in significant losses of the desirable stem material. The best achievable residue separation represented only a $2.2 \%$ increase in glucan content compared to normal combine fractionation. However, based on analytical analysis of the discreet cereal stover anatomical fractions (as in Figure 3 above), a 6\% glucan content increase is potentially achievable if a high fidelity separation of the chaff and straw streams can be achieved. This $6 \%$ glucan enrichment performance target is analogous to the targets shown in Figure 3, with the difference attributed to a different wheat variety and perhaps to a difference in the analytical technique. This project reinforced the need and potential benefits of separating the chaff and straw residue streams, but the limited success of this project also demonstrated the complexity of accomplishing high-fidelity separations.

The limitation of the empirical approach of the IDWR project is that residue fractionation is a fluid-flow phenomenon, involving the flow of biomass particles in the combine air stream, and understanding fluid flow on intuition alone is often impossible. Consequently, engineering fluid flow solutions without experimental or computational methods to visualize and/or simulate the fluid flow are rarely optimized. Therefore, it was realized at the onset of the current task that a computational engineering approach was essential for developing high-fidelity fractionation for the selective harvest. 
Computational engineering generally involves modeling, analysis and visualization for the solution of physical problems in design and development applications. This field is so broad that it can take on many different forms. For this selective harvest application, computational engineering included computational fluid dynamics (CFD), computer aided design (CAD) and visualization, all integrated into a framework referred to as virtual engineering. The integration capability of virtual engineering distinguishes it from traditional computational engineering approaches. With traditional approaches, the different engineering tools (e.g., CFD, CAD, visualization) generally exist as discrete software packages that are used independently of each other. Virtual engineering, on the other hand, consists of a framework that integrates the discrete tools into a common, interactive environment where they are seamlessly coupled together; this coupling provides a unique ability to perform engineering design simulations. The software foundation encompassing the virtual engineering and decision-making process is in a software package called VE-Suite (VE-Suite, 2005). For a detailed description of this virtual engineering approach to developing selective harvest technologies see Kenney 2005.

It was determined during model development that high-fidelity residue fractionation could be achieved with the insertion of an engineered baffle in the flow field that physically separates the straw and chaff streams. Therefore, the function of the model was to simulate the effect the baffle on the flow field, so that baffle designs could be evaluated based on its ability to accomplish the high-fidelity residue separation without adversely affecting the air flow and the ability of the machine to harvest grain. The primary components of the model are (1) the combine geometry, (2) a baffle design canvas (CAD tool) and (3) a CFD model of the singlephase air flow of the combine cleaning system, developed with the Fluent 6 software package (Fluent, 2004).

The process of performing a design simulation consists of the following steps. First, using the design canvas, create a baffle by defining its geometry and location within the design space. Second, submit the job to "build" the baffle in the virtual combine. Third, start the simulation. When the simulation is started, the CFD mesh (geometry) is automatically regenerated by Gambit (Fluent, 2004) to reflect the new geometry. After meshing, Fluent is automatically started and the CFD model is executed. When the model finishes execution, the new CFD data set is automatically loaded into VE-Suite where it is displayed to visualize and interpret the results. Since the CFD model simulates air flow behavior, and not residue fractionation, the determination of baffle performance requires interpretation. However, as will be shown in the results section below, interpretation is very intuitive to one familiar with combine performance. This process is repeated to evaluate different baffle designs.

After a baffle design was selected from the model simulation, a baffle was built into the INL single-pass research combine for testing. The single-pass harvester is shown in Figure 4 and consists of a New Holland CR960 rotary grain combine, two Redekop wagons and a Redekop chaff blower (Redekop, 2005). The two wagons were towed behind the combine, with one wagon collecting the straw stream and the other wagon collecting the chaff stream. The Redekop chaff blower was installed at the end of the cleaning shoe to collect the chaff stream and blow it into the chaff wagon. The straw stream flowed from the beater bar into the straw chopper where it was chopped and then blown into the straw wagon. The single-pass harvester was used to harvest Challis soft-white spring wheat, and the chaff and straw streams collected in the wagons. Tests were conducted both with the baffle and without the baffle to quantify the separation fidelity. Straw and chaff samples were taken from each wagon and later fractionated using a forage particle separator (ANSI/ASAE, 2001) to quantify the sample constituents. 

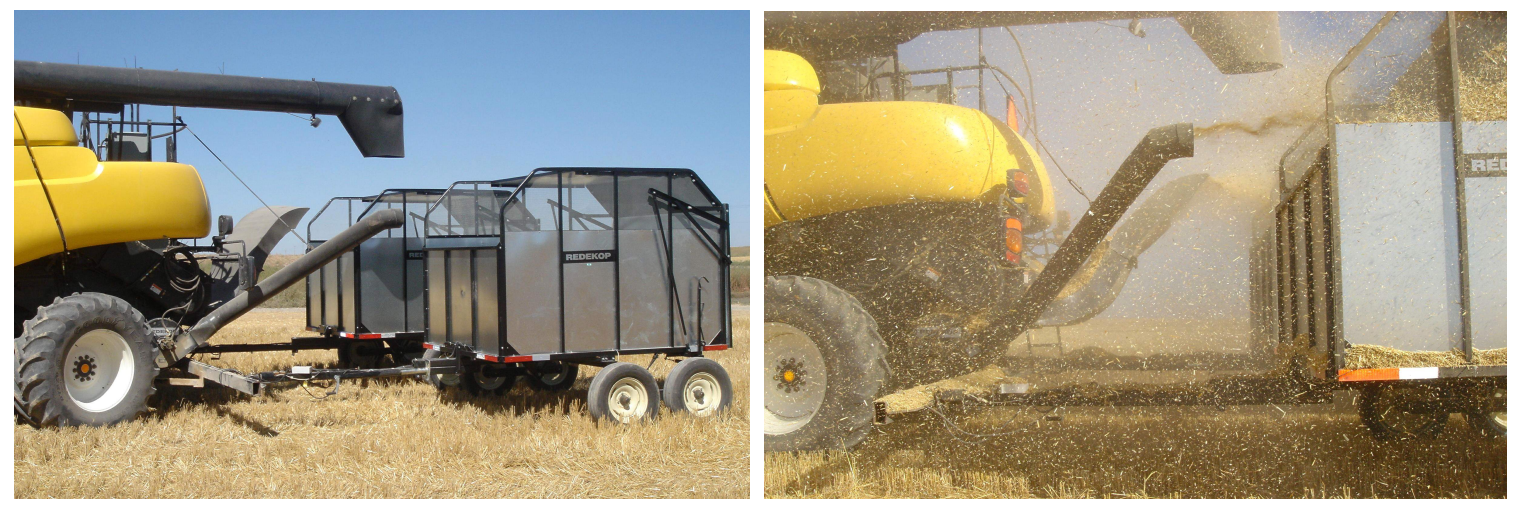

Figure 4. INL selective harvest test combine. In the picture on the right, the near wagon is collecting the chaff stream and the far wagon is collecting the straw stream.

\section{Results and Discussion}

\section{Selective Harvest Design}

The airflow simulation of normal combine performance is shown in Figure 5. This figure shows the combine geometry with the color contour plot of the CFD data. The contour plot represents the airflow through the combine separation and cleaning chamber. The contour interval legend in the lower left corner shows the color gradient where dark blue represents the lowest velocity and red the highest velocity (for black-and-white prints the dark regions represent the lowest velocities and the light regions represent the highest velocities). Rather than velocity magnitudes, it is the air stream pattern that is most notable. In particular, two airstreams split the chamber - one along the cleaning shoe that helps carry the chaff stream out of the combine and the other that follows the upper contour of the chamber that helps carry the straw stream out of the combine. The problem with this configuration is that although the chaff and straw streams are separated at the front end of the machine during threshing, they converge at the back end of the machine as the two streams are discharged. In the configuration of this model and the test combine, the two streams do not discharge through the same opening; however, the two opening are only separated by about ten inches. Consequently, mixing of the two streams occurs, particularly straw falling down into the chaff stream. Evidence of this mixing is provided in the discussion below.

The solution to this mixing problem and the objective of the residue separator design is to insert a baffle that physically separates the chaff and straw stream and eliminates the opportunity for mixing. This scenario is demonstrated in Figure 6(a), where a baffle is inserted into the geometry, extending from the straw stream discharge to the end of the beater bar where the straw stream enters the combine airstream. The CFD solution for this baffle scenario provides visualization of the airstream behavior with this baffle in place. The visualization capability of the VE model allows us to predict the combine performance for this design scenario. This baffle design completely cut off the upper air stream that carries the straw stream out of the combine. As a result, the straw will hold up in the recirculation zone behind the beater and accumulate to the point that it would plug the machine. It is more difficult to predict the effect on the chaff stream, but it is likely that the additional back pressure caused by the compression of the upper air stream will collapse the bed on the cleaning shoe severely affecting grain loss and cleaning. This is clearly a bad design. An interesting side note, though, is that this baffle design was one of the empirical approaches evaluated in the IDWR project mentioned above. This test occurred 


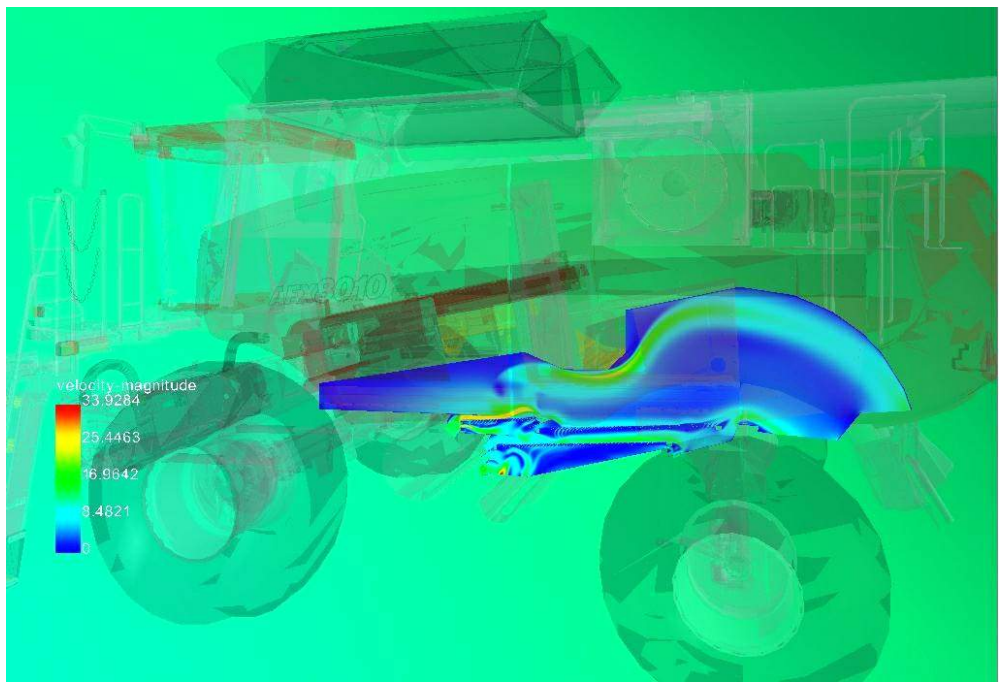

Figure 5. Virtual engineering model showing the simulated flow field of the cleaning system performance of a rotary combine.

well before the modeling capability of the current project, and prior to modeling the airstream, the thought was that the straw was carried out of the machine by the momentum imparted by the beater bar, not by the air stream. The results of this test were just as predicted by this model.

Although a full baffle design would guarantee a perfect separation of the two residue streams, the simulation shows that this design would ruin the combine performance. This simulation also clearly establishes a design requirement that the baffle not impede the upper airstreampredicted by the model. Therefore, a partial-length baffle was designed into the virtual combine and the simulation was run to evaluate the design. The results of this simulation are shown in Figure 6(b). A side-by-side comparison with the simulation of the unbaffled scenario shows the baffle to have little effect on the flow field behavior. Although a partial baffle still allows some open space between the two residue streams in which mixing could occur, it satisfies the two main design requirements in that it eliminates the potential for mixing at the discharge and it does not impede the predominant air streams that are significant to combine performance. Accordingly, this baffle design was selected for testing.

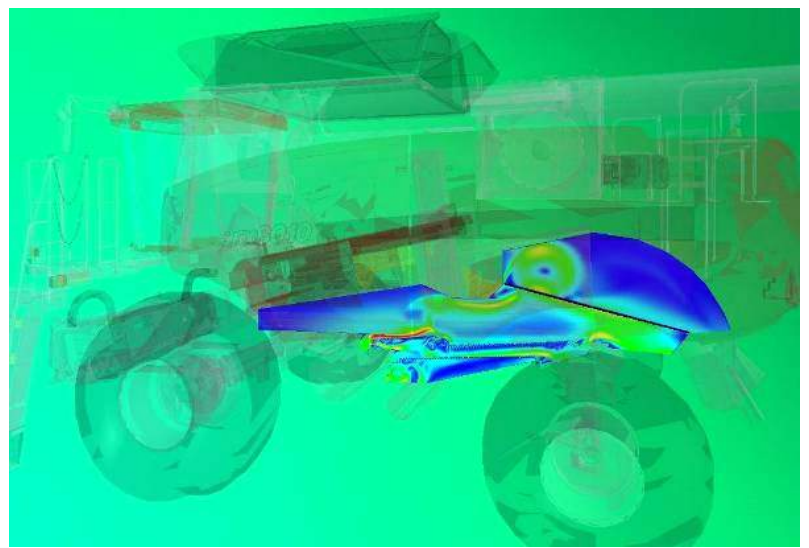

(a)

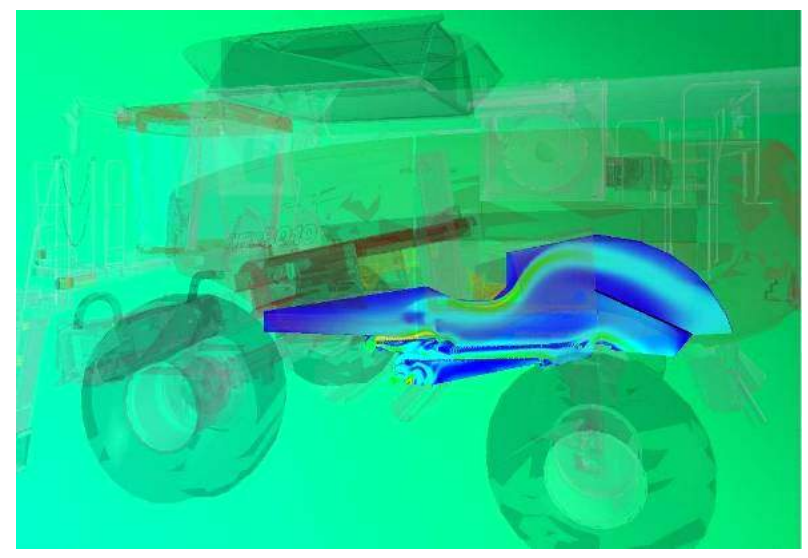

(b)

Figure 6. Virtual engineering model showing the simulation of a full-length baffle (a) and the final baffle design (b). 


\section{Selective Harvest Performance}

Field tests were performed to collect the data necessary to evaluate the selective harvest design. Tests were run both with and without the baffle separator installed in the INL research combine, and the chaff and straw streams were collected in the wagons during harvest of Challis soft white spring wheat. When the wagons were full they were dumped (see Figure 7), leaving chaff and straw piles behind from which samples were taken for laboratory analysis.

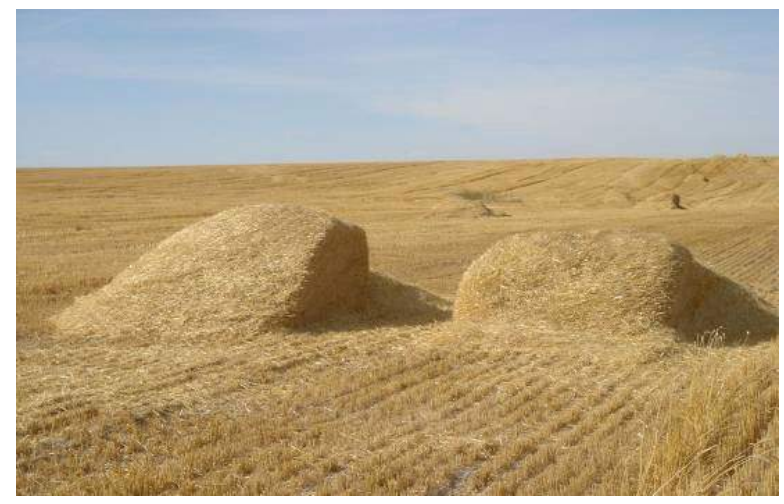

Figure 7. Straw and chaff piles from the selective harvest field tests.

The tests run without the residue separator quickly revealed the poor separation of the straw and chaff streams. Visual examination of the straw and chaff piles showed very poor and inadequate separation of the straw and chaff. Pictures of the edge profile of a straw and chaff pile collected without the baffle separator are shown in Figure 8. These pictures show little difference in the two piles. In fact, both piles look like straw, but close examination reveals more chaff in one than the other. In contrast, after the baffle was installed, the two piles looked distinctly unique - the straw was clearly straw and the chaff, although it stilled contained a small fraction of straw material, was clearly chaff. Pictures of these piles are also shown in Figure 8.

The visual observation of the baffle performance was confirmed and quantified by laboratory screening analysis. The objective of screening was not to determine the particle size distribution but to determine the anatomical composition of the collected residue streams. Therefore, although the screen shaker separates the samples into six different fractions based on particle size, the fractions were consolidated into two fractions based on anatomical composition. The screening results of the chaff wagon sample are shown in Figure 9(a). The "straw" fraction of the chaff wagon sample is the combined material from the largest two screens, which predominantly consisted of intact internodal stem and node material. The "chaff" fraction of the chaff wagon sample is the combined material from the smallest three screens and the pan that collects the fines that pass through all of the screens. The chaff fraction consists primarily of the material commonly referred to as chaff (hull, leaves and awns), along with a smaller fraction of sheath material, some nodes, and small, broken pieces of stem. The screen analysis shows a significant improvement in straw/chaff separation by the installation of a residue separator (baffle), reducing the amount of straw in the chaff stream from $36 \%$ to $7 \%$. This $7 \%$ is attributed to the straw that spears down through the concaves and concave extensions and therefore enters the chaff stream well before the baffle. The occurrence of spearing was confirmed using a "kill-stall" method where the combine is shut off while it is threshing so that the biomass stops where it is in the machine at the time of the stall. After the kill-stall, straw was observed in the chaff material beneath the rotors, as evidence of spearing. 


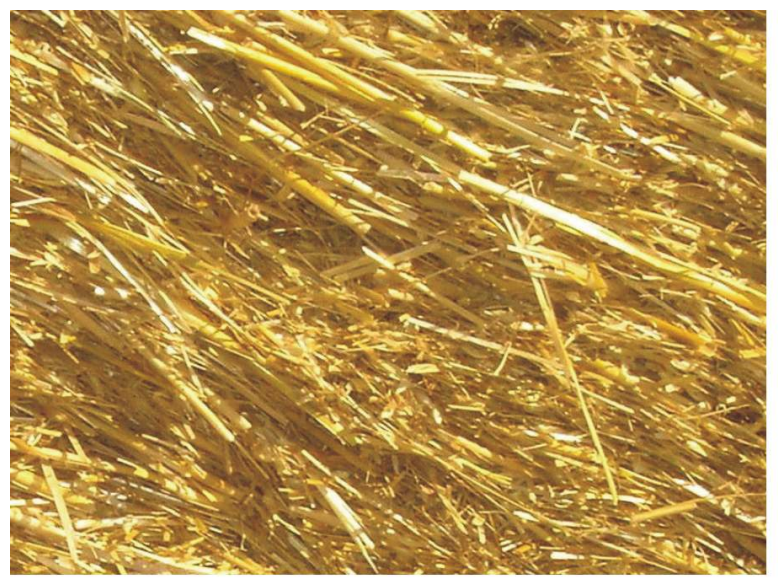

(a)

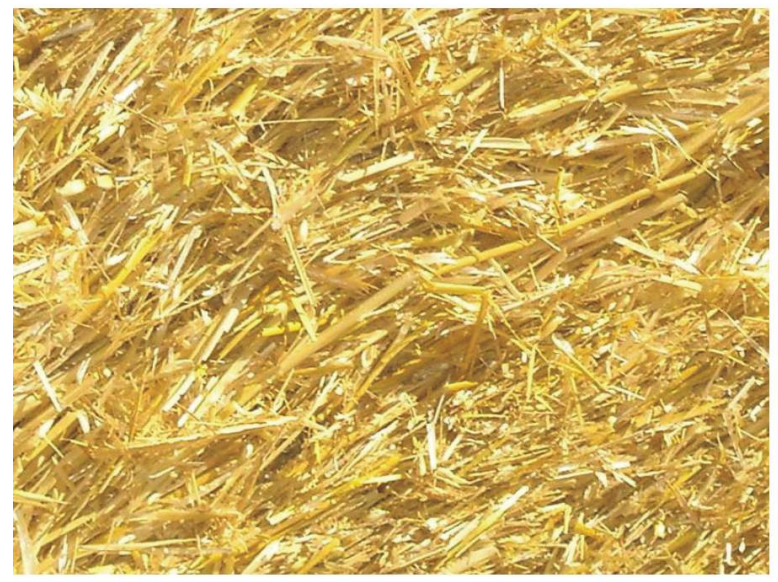

(c)

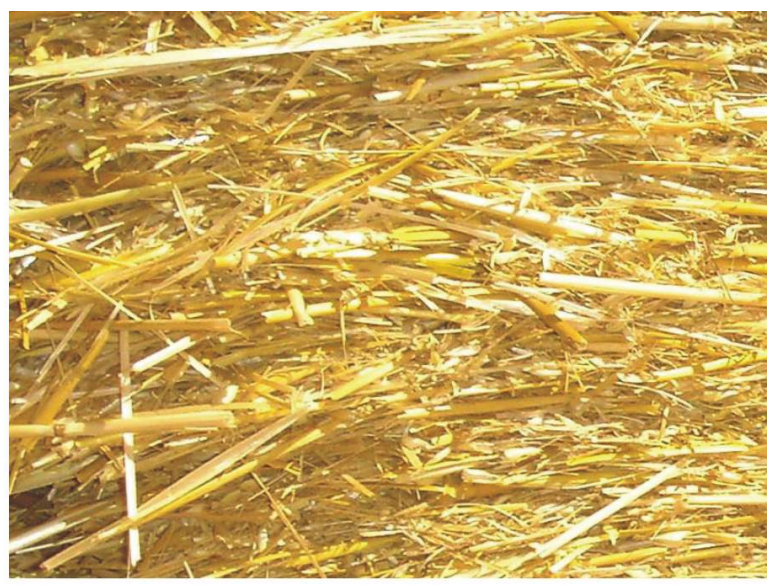

(b)

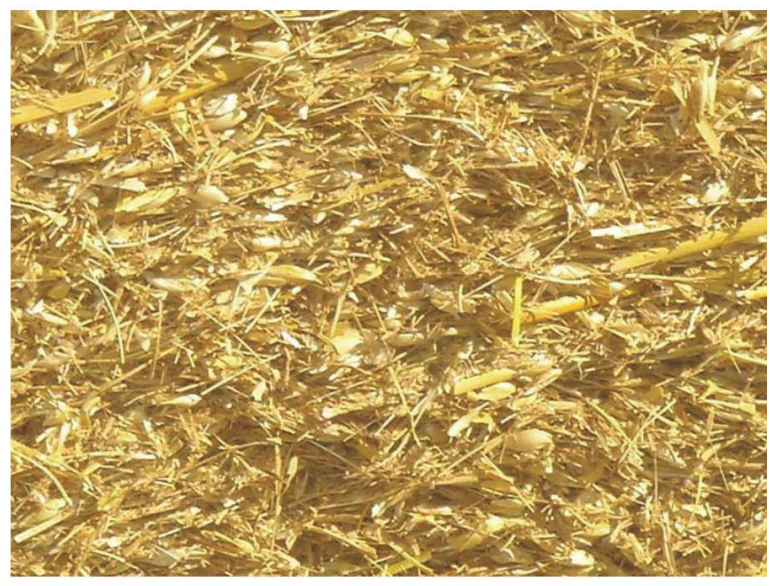

(d)

Figure 8. Pictures of the straw (a) and chaff (b) fractions resulting from normal combine fractionation, and the straw (c) and chaff (d) fractions resulting from the baffle separator.

The screening results of the straw wagon sample are shown in Figure 9(b). Fraction A of the straw wagon sample is the consolidated material from the largest two screens and fraction $B$ is the consolidated material from the smallest three screens and the pan. However, fractions $A$ and $B$ are not indicative of anatomical fractions, as were the straw and chaff fractions of the chaff wagon screen analysis. Since the straw stream discharges through the straw chopper and gets chopped up, even the fractions of the smallest screens are dominated by straw material. The screen analysis of the straw wagon sample therefore represents more of a size distribution rather than an anatomical distribution as in the chaff wagon analysis. However, some chaff did exist on one of the smaller screen fractions, but it was intermixed with finely chopped straw particles and therefore unquantifiable by screening. Nonetheless, the chaff material is included in Fraction $B$ of the screen analysis, so changes in the percentage of chaff due to the baffle should be reflected in the screen analysis. The screening results show no difference in the two fractions with or without the baffle separator. Since Fraction B, which includes any chaff material in the sample, did not change we can conclude that chaff mixing with the straw is not a significant problem. The chaff that does end up in the straw stream is there because it was trapped by the straw during threshing so it did not fall through the concaves and concave extensions into the chaff stream. 


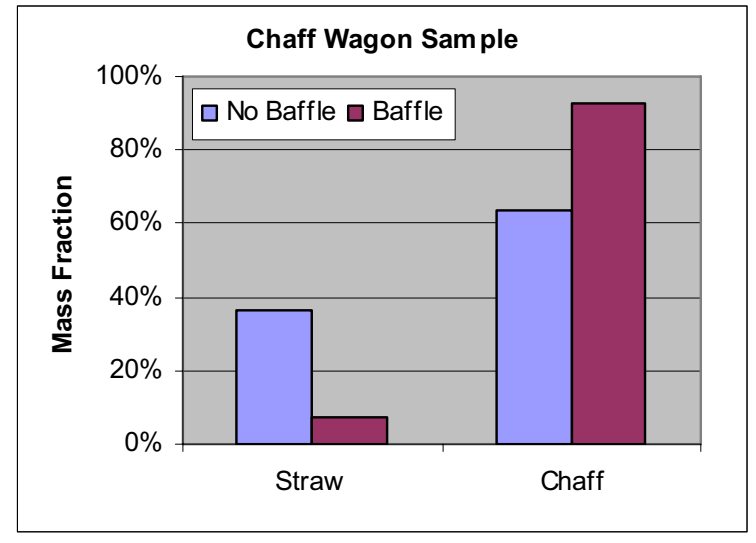

(a)

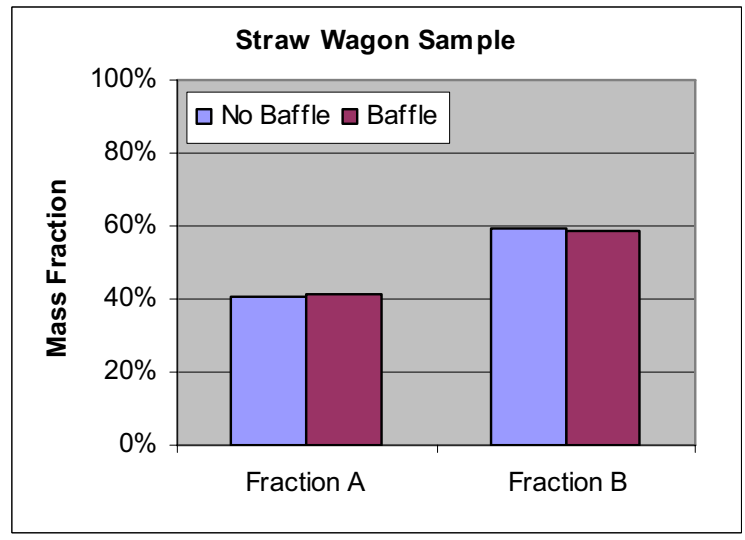

(b)

Figure 9. Laboratory Screening results comparing the separation fidelity of normal combine fractionation (no baffle) and the engineered selective harvest fractionation (baffle). A before/after comparison of the chaff fraction is shown in (a) and the straw fraction in (b).

\section{Conclusion}

This paper described the engineering design and testing of a selective harvest combine for wheat straw. Practical harvester performance targets were established from empirical evidence of feedstock quality potential, and using virtual engineering technology selective harvest designsimulations were conducted to evaluate the performance of an engineered residue separator. This work showed that with a relatively simple design implementation a rotary combine is capable of high-fidelity residue separation necessary for selective harvest. Specifically, the engineered baffle separator did a remarkable job of effecting high-fidelity separation of the straw and chaff residue streams, improving the chaff stream purity from $64 \%$ to $93 \%$ and increasing the straw stream yield by the corresponding amount. This work provided strong evidence for the ability to achieve selective harvest objectives, but whether this technology will be of commercial significance requires additional analysis of the compositional differences of the two residue streams and the corresponding effect on ethanol yield and feedstock pretreatment effects. Additional analysis should also include evaluating the value for selective harvest of other feedstocks (e.g., corn stover). Furthermore, although this study successfully demonstrated high-fidelity selective harvest, the harvester efficiency was dramatically reduced by the limitations of the residue handling systems. Therefore, selective harvest machinery efficiencies must also be improved for this technology to become commercially viable (we have already identified potential improvements in residue that may significantly improve harvester efficiency). Finally, this study demonstrated selective harvest using a rotary combine (the other main type of combine is a conventional combine), and since the residue fractionation may be significantly different for a conventional machine, some level of analysis to evaluate machine configuration effects should be performed before the value selective harvest can be broadly categorized.

\section{Acknowledgements}

This work was supported by the U. S. Department of Energy Office of the Biomass Program and the INL Laboratory Directed Research \& Development (LDRD) Program under DOE Idaho Operations Office contract DE-AC07-05ID14517. 


\section{References}

ANSI/ASAE Standards 47th Ed. 2001. S424.1 - Method of determining and expressing particle size of chopped forage materials by screening. 576 - 578. St. Joseph, Mich.: ASAE.

Fluent. 2004. Fluent. Ver. 6.2.16. Lebanon, NH: Fluent, Inc.

Hess, J. R., et al. 2004. Selective Harvest of Higher Value Wheat Straw Components. Final Project Report. Boise, ID: Idaho Department of Water Resources.

Hoskinson, R. L. and J. R. Hess. 2004. A Single Pass Multi-component Harvester for Small Grains. ASAE Paper No. 141161. St. Joseph, Mich.: ASAE.

Kenney, K. L., C. T. Wright and K. M. Bryden. 2005. Virtual Engineering Approach to Developing Selective Harvest Technologies. ASAE Paper No. 056046. St. Joseph, Mich.: ASAE.

Quick, G. 2002. Single-pass corn and stover harvesting developments. Bioenergy 2002 Conference, Boise, ID. September 23 - September 25, 2002.

Redekop Manufacturing Co. 2005. Saskatoon, SK, Canada. Available at: http://www.redekopmfg.com. Accessed 24 Oct 2005.

Shinners, K. J., G. S. Adsit, B. N. Binversie, and M. F. Digman. 2005. Characteristic performance and yields using a single-pass, split-stream maize grain and stover harvester. ASAE Paper No. 056051. St. Joseph, Mich.: ASAE.

VE-Suite. 2005. Available at http://www.ve-suite.org. Accessed 09 May 2005. 